\title{
Pre-treatment Neutropenia in Children and Adolescents with Autoimmune Hyperthyroidism
}

\author{
(D) Melissa Kaori S. Litao, (D) Ana Gutierrez Alvarez, (D) Bina Shah \\ New York University Faculty of Medicine, Department of Pediatrics, Division of Pediatric Endocrinology, New York, USA
}

\begin{abstract}
What is already known on this topic?
Untreated hyperthyroidism can cause neutropenia and the prevalence in adults is reported to range between 14-18\%. To our knowledge, there is currently no data on this in children and adolescents.
\end{abstract}

\section{What this study adds?}

This study describes the prevalence of pre-treatment neutropenia in autoimmune hyperthyroidism in children and adolescents at presentation, which was found to be $16 \%$. Pre-existing neutropenia in the study population resolved in the short term and did not worsen with thionamides, while no other thionamide-treated patient developed drug-associated neutropenia.

\begin{abstract}
Objective: Neutropenia can occur in untreated autoimmune hyperthyroidism (AIH) or in association with treatment with the anti-thyroid drug, methimazole (MMI). Starting MMI in children and adolescents with AIH and pre-existing neutropenia could thus be worrisome. The aim was to describe the prevalence of neutropenia in pediatric AIH, prior to antithyroid drug therapy and to assess the effect of antithyroid drugs on neutrophil count.

Methods: Patients with AIH attending a pediatric endocrinology clinic were retrospectively reviewed. Absolute neutrophil count (ANC) data at presentation and during anti-thyroid treatment for up to 24 weeks was collected. AIH was defined as elevated free thyroxine (fT4) or free tri-iodothyronine (fT3), suppressed thyroid stimulating hormone, and positive thyroid autoantibodies. Neutropenia was defined as ANC $<1500$ cells/ $\mu \mathrm{L}$.

Results: Thirty-one patients (71\% female) were included with a median interquartile range (IQR) age of 14.71 (11.89 17.10) years. Neither fT4 nor fT3 levels correlated with ANC at presentation $\left(r_{s}=0.22, p=0.24\right.$ and $r_{s}=0.13, p=0.54$, respectively). 26/31 (84\%) had normal baseline ANC. None developed neutropenia with thionamides. 5/31 (16\%) had baseline neutropenia (median ANC 1,200/ $\mu \mathrm{L}$; IQR 874-1200). Four of these five started MMI at diagnosis while one was started on propranolol only but MMI was started one week later. All five normalized ANC within 24 weeks.

Conclusion: In this cohort, $16 \%$ of AIH patients had neutropenia at presentation, but this resolved in the short term and did not worsen with thionamides. Thionamides may be used with caution in these patients with close monitoring of blood counts.

Keywords: Hyperthyroidism, neutropenia, thionamides, methimazole, agranulocytosis
\end{abstract}

\section{Introduction}

Autoimmune hyperthyroidism (AIH) is the most common cause of hyperthyroidism in the pediatric population, and methimazole (MMI) is the anti-thyroid drug (ATD) of choice
(1). Agranulocytosis is a known rare, but serious, adverse reaction to ATD, and has been reported to occur in 0.1-0.5\% of patients with Graves' disease after initiation of therapy (2). 
However, untreated hyperthyroidism per se can cause hematologic abnormalities, including anemia, leukopenia, thrombocytopenia, or rarely pancytopenia. This has been reported several times in the literature, generally in the adult population. Most of these patients were treated with thionamides, with blood counts improving after achievement of euthyroidism $(3,4,5,6,7,8,9,10)$. In particular, the presence of baseline neutropenia in a patient presenting with hyperthyroidism could be worrisome for the clinician, given the concern for potential agranulocytosis as a side effect of ATDs.

A prospective study by Aggarwal et al (6) found that among newly diagnosed adult patients with Graves' disease $(n=206), \quad 14.1 \%$ had pre-treatment neutropenia. The study also found that neutrophil counts increased after treatment with antithyroid drugs and that this was related to a reduction in thyroid hormone levels. To our knowledge, there is currently no pediatric data on this subject.

\section{Objectives}

The objectives of this study were to describe the prevalence of neutropenia in children and adolescents with AIH prior to treatment with antithyroid drugs and to assess the effect of antithyroid drugs on the neutrophil count.

\section{Methods}

This was a retrospective study of patients diagnosed with AIH who were seen at the Pediatric Endocrinology clinic from January 1, 2005 to May 31, 2019. Inclusion criteria were those who have never received ATD, those who had been off ATD for more than three months due to noncompliance, those who succeeded initially in being tried off ATD for more than three months but went into relapse afterwards, and those who underwent radioactive iodine (RAI) therapy or surgical thyroidectomy but went into relapse at least three months after these procedures. Group A was the control group and consisted of those who were not found to have neutropenia at baseline and Group B consisted of those with neutropenia at baseline. Those for whom pretreatment data were unavailable were excluded.

Data up to 24 weeks after treatment was collected. To be diagnosed with AIH, patients must have had elevated free thyroxine (fT4) [normal range (NR): 0.7-1.5 ng/dL] or free tri-iodothyronine (fT3) (NR: 1.71-3.71 pg/mL), suppressed thyroid stimulating hormone (TSH) (NR: 0.4-4.5 mIU/L), and at least one positive thyroid autoantibody Neutropenia was defined as absolute neutrophil count (ANC) $<1,500$ cells/ $\mu \mathrm{L}$ (11). Data collected included patient age, sex, ethnicity, presenting signs and symptoms, levels of TSH, fT4, fT3, anti-thyroglobulin (anti-TG) antibody, anti-thyroperoxidase (anti-TPO) antibody, TSH receptor antibody (TRAb), thyroidstimulating immunoglobulin (TSI), complete blood count including white blood cell with differential count, red blood cell count, platelet count, as well as levels of anti-neutrophil cytoplasmic antibodies (ANCA). Patients were divided into two group based on baseline ANC. Group A had normal baseline ANC while Group B had neutropenia.

The study protocol was reviewed and approved by the New York University (NYU) School of Medicine's Institutional Review Board as Exempt Category 4 (study \# i19-00627). As this was a retrospective chart review which did not make use of identifiable health information and provided no more than minimal risk to the subjects, informed consent was not necessary, and a request for waiver of authorization to use identifiable health information for research was approved by the NYU Faculty of Medicine's Institutional Review Board in accordance with 45 CFR. 164.512.

\section{Statistical Analysis}

This was primarily a qualitative study that looked at the prevalence of pre-treatment neutropenia in newly diagnosed patients with pediatric AIH. Statistical analysis was done to find whether fT4 or fT3 correlated with pre-treatment ANC. None of the variables had normally distributed data, thus a Spearman correlation test was performed using the SciPy library program (https://www.scipy.org/). Median values for age, fT4, fT3 and ANC were obtained using the same program

\section{Results}

A total of 31 patients with AIH were included. Six patients were excluded due to absence of pre-treatment data. All patients were newly diagnosed and had never received ATD. Median age was 14.71 years (0.02-19.2) and 22 (71\%) were females. Ethnicity was: $48 \%$ Hispanic $(n=15) ; 32 \%$ Asians $(n=10) ; 10 \%$ Caucasians $(n=3) ; 6 \%$ African Americans $(n=2)$; and $3 \%$ Middle Eastern $(n=1)$. All had positive thyroid antibodies: five (16\%) with TRAb/TSI only, four (13\%) with anti-TPO and/or anti-TG, nine (29\%) with TRAb/ TSI and either anti-TPO or anti-TG, and nine (29\%) were positive for all three. Four (13\%) only had TSI measured and were positive. Family history of thyroid disease was present in 15 out of 29 (51.7\%) with no data available in two. Neither fT4 nor fT3 levels significantly correlated with ANC at presentation $\left(r_{s}=0.22, p=0.24\right.$ and $r_{s}=0.13, p=0.54$, respectively) (Table 1, Figures 1 and 2). 
In the cohort 26/31 patients (Group A, 84\%) had normal baseline ANC (median 3,800/ $\mu \mathrm{L} ; 2,100-9,700$ ) and $77 \%$ $(n=20)$ were females. In Group A median fT4 was 3.47 $\mathrm{ng} / \mathrm{dL}(1.5-10.12)$ and fT3 $12.2 \mathrm{pg} / \mathrm{mL}(4.6-29.8)(\mathrm{n}=23)$. None of these patients developed neutropenia after starting thionamides.

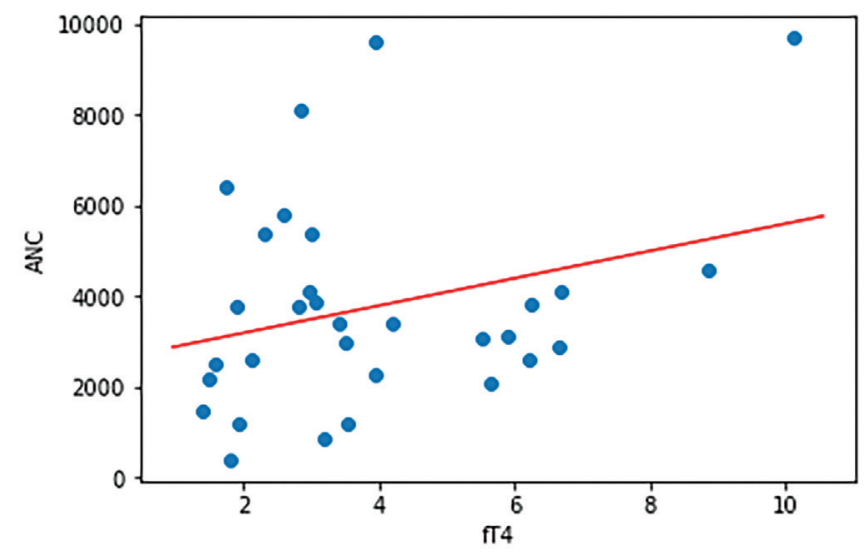

Figure 1. Lack of correlation between pre-treatment free thyroxine and absolute neutrophil count

ANC: absolute neutrophil count, fT4: free thyroxine
Five out of 31 patients (16\%) had baseline neutropenia (median 1,200/ $\mathrm{L} ; 400-1,458$ ) and constituted Group B of whom $40 \%(n=2)$ were females. Median fT4 was $1.92 \mathrm{ng} / \mathrm{dL}$ (1.4-3.55) and fT3 $8.3 \mathrm{pg} / \mathrm{mL}(6.1-19)(\mathrm{n}=3)$. In 4/5 patients, MMI was started at diagnosis. The other patient started on propranolol only but MMI was introduced one week later. All

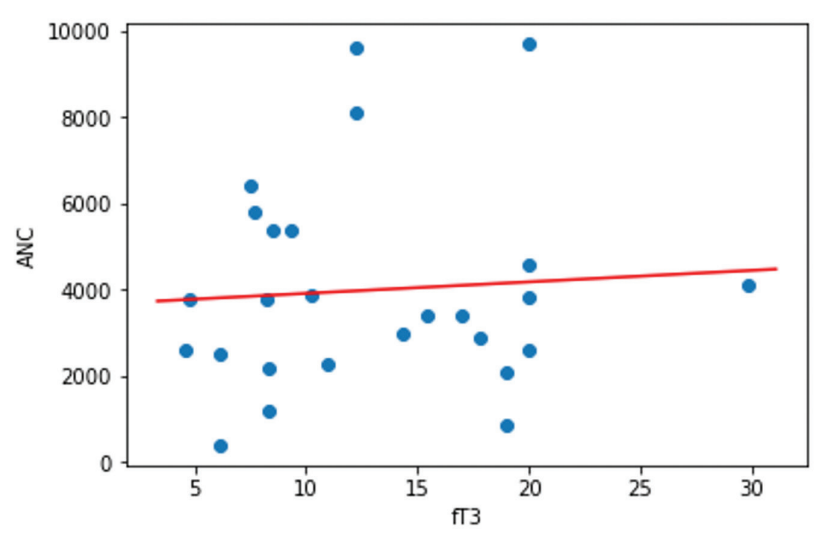

Figure 2. Lack of correlation between pre-treatment free tri-iodothyronine and absolute neutrophil count

ANC: absolute neutrophil count, fT3: free tri-iodothyronine

\begin{tabular}{|c|c|c|c|c|}
\hline & $\mathrm{n}$ & Total & $\begin{array}{l}\text { Group A } \\
n=26(84 \%)\end{array}$ & $\begin{array}{l}\text { Group B } \\
\mathrm{n}=5(16 \%)\end{array}$ \\
\hline Age in years & 31 & $14.71(0.02-19.2)$ & $14.6(0.02-19.2)$ & $16.58(4.8-18.75)$ \\
\hline Sex & 31 & & & \\
\hline Males & & $9(29 \%)$ & $6(23 \%)$ & $3(60 \%)$ \\
\hline Females & & $22(71 \%)$ & $20(77 \%)$ & $2(40 \%)$ \\
\hline Ethnicity & 31 & & & \\
\hline Hispanic & & $15(48 \%)$ & $14(54 \%)$ & $1(20 \%)$ \\
\hline Asian & & $10(32 \%)$ & $7(27 \%)$ & $3(60 \%)$ \\
\hline Caucasian & & $3(10 \%)$ & $3(12 \%)$ & 0 \\
\hline African American & & $2(6 \%)$ & $1(4 \%)$ & $1(20 \%)$ \\
\hline Middle Eastern & & $1(3 \%)$ & $1(4 \%)$ & 0 \\
\hline Thyroid antibodies & 31 & & & \\
\hline TRAb/TSI only & & $5(16 \%)$ & $4(15 \%)$ & $1(20 \%)$ \\
\hline anti-TPO or anti-TG only & & $4(13 \%)$ & $3(12 \%)$ & $1(20 \%)$ \\
\hline TRAb/TSI + anti-TPO or anti-TG & & $9(29 \%)$ & $8(31 \%)$ & $1(20 \%)$ \\
\hline All three & & $9(29 \%)$ & $8(31 \%)$ & $1(20 \%)$ \\
\hline Only TSI measured (positive) & & $4(13 \%)$ & $3(12 \%)$ & $1(20 \%)$ \\
\hline Family history of thyroid disease & 29 & $15(52 \%)$ & $13 / 24(54 \%)$ & $2 / 5(40 \%)$ \\
\hline fT4 (N: 0.7-1.5 ng/dL) & 31 & $3.20(1.4-10.12)$ & $3.47(1.5-10.12)$ & $1.92(1.4-3.55)$ \\
\hline fT3 (N: $1.71-3.71 \mathrm{pg} / \mathrm{mL})$ & 26 & $11.60(4.6-29.8)$ & $12.2(4.6-29.8)^{*}$ & $8.3(6.1-19)^{* *}$ \\
\hline ANC (cells/ $\mu \mathrm{L})$ & 31 & $3,400(400-9,700)$ & $3,800(2,100-9,700)$ & $1,200(400-1,458)$ \\
\hline
\end{tabular}

Median (range) or $\mathrm{n}(\%)$.

*Group A: 23/26 patients had fT3 levels.

* *Group B: 3/5 patients had fT3 levels.

TSI: thyroid-stimulating immunoglobulin, fT4: free thyroxine, fT3: free tri-iodothyronine, ANC: absolute neutrophil count, TRAb: thyroid stimulating hormone receptor antibody, anti-TPO: anti-thyroperoxidase, anti-TG: anti-thyroglobulin 
five cases normalized their ANC within 24 weeks and 4/5 cases had normal ANC by four weeks. However one of these four developed a transient drop in ANC at week nine which again normalized by 21 weeks; the reason for this transient decrease could not be elucidated, as it occurred despite normalizing fT4 and fT3, and was not associated with an increase in MMI dose or any other documented stressor. The remaining patient continued to have neutropenia after 12 weeks of therapy but had normalized by 24 weeks. In addition, 3/5 patients were checked for ANCA and all were negative (Figure 1 and Table 2).

\section{Discussion}

In this study, $16 \%$ of pediatric patients with AIH were found to have neutropenia prior to initiating treatment with ATDs, similar to studies in adults which have reported prevalences between $14-18 \%(6,12)$. Most patients in this study who had pre-treatment neutropenia (3/5 patients) had ANC >1,000 cells/ $\mu \mathrm{L}$, while one had moderate neutropenia ( $874 \mathrm{cells} / \mu \mathrm{L}$ ) and one had severe neutropenia (400 cells/ $\mu \mathrm{L}$ ). In an adult study by Aggarwal et al (6), 14.1\% of patients with Graves' disease $(n=206)$ had pretreatment neutropenia, although the study used an ANC cutoff of $<2000$ cells/ $\mu \mathrm{L}$; mean ANC in these neutropenic patients was $1,600 \pm 300 \mathrm{cells} / \mu \mathrm{L}$. Aggarwal et al (6) found that neutrophil counts in patients with pre-treatment neutropenia increased after initiation of ATDs and euthyroidism in these patients was achieved after a median time period of 55 days. The increase in ANC was found to be related to a reduction in thyroid hormone levels. In our study, neither fT4 nor fT3 levels were found to correlate with ANC at baseline. Although Aggarwal et al (6) used an ANC cutoff of $<2,000$ cells $/ \mu \mathrm{L}$, in pediatrics, neutropenia is conventionally defined as an ANC $<1,500$ cells/ $\mu \mathrm{L}$, so we opted to use this cutoff in our study (11). Gangadharan et al (13) reported a case of a 13 year old boy with Graves' disease and a pre-treatment ANC of $<1,500$ cells $/ \mu \mathrm{L}$. The child was treated with propranolol with Lugol's iodine and neutrophil counts improved after 16 days of treatment, upon which carbimazole was started.

Neutropenia has been reported to occur in less than $0.3 \%$ of adults with Graves' disease upon starting MMI, but the prevalence in children is unclear $(14,15)$. In a study by Rabon et al (15), the pediatric patients who developed neutropenia after starting MMI (9 out of 251) had mild neutropenia, with none having an ANC $<1,000$ cells $/ \mu$ L. Rivkees et al (14) studied 100 consecutively treated pediatric patients with Graves' disease, of whom two developed moderate neutropenia (500 and 750 cells/ $\mu \mathrm{L}$ ). These studies looked at the overall rates of adverse events with MMI and did not go into particulars as to how the patients with neutropenia were managed, but generally, the patients who developed adverse effects with MMI stopped the medication and underwent definitive therapy, such as surgery or RAI. MMIassociated agranulocytosis is thought to be due to either direct toxicity when the drug is oxidized by neutrophils to reactive metabolites, or to immune-mediated mechanisms, which may include ANCA; these are generally believed to be idiosyncratic reactions $(16,17,18)$. However, a large study by Takata et al (19) found that agranulocytosis was significantly more common in those who received a higher daily dose of MMI $(0.8 \%$ in those who received $30 \mathrm{mg}$, $\mathrm{n}=2087 ; 0.3 \%$ in those who received $15 \mathrm{mg}, \mathrm{n}=2,739$; $p<0.001$ ), suggesting that there could be a dose-dependent mechanism. In our study, none of the patients who had a normal ANC at baseline (Group A) developed neutropenia after treatment with thionamides. Patients who had pretreatment neutropenia (Group B) were started on standard doses of MMI (Table 2), and none of them developed severe agranulocytosis with treatment.

Several studies have reported not only neutropenia but pancytopenia as a complication of poorly controlled Graves' disease $(3,4,5,7,8,10,20,21,22,23,24)$ which responded to

\begin{tabular}{|c|c|c|c|c|c|c|c|c|c|c|c|c|}
\hline & \multirow{2}{*}{$\begin{array}{l}\text { Age } \\
\text { (years), } \\
\text { sex }\end{array}$} & \multirow[t]{2}{*}{ Ethnicity } & \multirow{2}{*}{$\begin{array}{l}\text { Baseline } \\
\text { ANC } \\
\text { (cells/uL) }\end{array}$} & \multirow{2}{*}{$\begin{array}{l}\text { Baseline } \\
\text { fT4 (ng/dL) }\end{array}$} & \multirow{2}{*}{$\begin{array}{l}\text { Baseline } \\
\text { fT3 }(\mathrm{pg} / \mathrm{mL})\end{array}$} & \multicolumn{2}{|l|}{ Treatment } & \multicolumn{5}{|c|}{ ANC response } \\
\hline & & & & & & $\begin{array}{l}\text { MMI (mg } \\
\text { daily dose) }\end{array}$ & $\begin{array}{l}\text { Propranolol } \\
\text { (mg TID) }\end{array}$ & $\begin{array}{l}2-4 \\
\text { wks }\end{array}$ & $\begin{array}{l}4-8 \\
\text { wks }\end{array}$ & $\begin{array}{l}8-12 \\
w k s\end{array}$ & $\begin{array}{l}12-20 \\
\text { wks }\end{array}$ & $\begin{array}{l}20-24 \\
\text { wks }\end{array}$ \\
\hline Patient 1 & $18.6, \mathrm{M}$ & A & 1458 & 1.4 & - & $5 *$ & - & - & 1900 & 1800 & 1900 & 1500 \\
\hline Patient 2 & $16.6, \mathrm{M}$ & $\mathrm{AA}$ & 874 & 3.2 & $>19$ & 20 & 20 & 1800 & 1500 & 1300 & 1700 & - \\
\hline Patient 3 & $4.8, \mathrm{~F}$ & A & 400 & 1.79 & 6.1 & $2.5 * *$ & $1.25 * *$ & 4170 & 3850 & 5370 & 2270 & - \\
\hline Patient 4 & $18.7, \mathrm{M}$ & $\mathrm{H}$ & 1200 & 1.92 & 8.3 & 20 & - & - & - & 1400 & - & 1700 \\
\hline Patient 5 & $14.7, \mathrm{~F}$ & A & 1200 & 3.55 & - & 30 & - & 2600 & 3800 & 2500 & - & - \\
\hline \multicolumn{13}{|c|}{$\begin{array}{l}\text { *MMI x } 1 \text { month then PTU } 100 \text { mg BID. } \\
\text { * Propranolol monotherapy x } 1 \text { week before adding MMI. } \\
\text { A: Asian, AA: African American, H: Hispanic, M: male, F: female, ANC: absolute neutrophil count, fT4: free thyroxine, fT3: free tri-iodothyronine, wks: weeks, MMI: } \\
\text { methimazole }\end{array}$} \\
\hline
\end{tabular}


ATDs, with or without RAI. In one case report (10), although pancytopenia improved with ATDs, there was a recurrent increase in thyroid hormone levels and pancytopenia after four months, upon which subtotal thyroidectomy was performed. The patient's pancytopenia then resolved with good control of thyroid function.

The mechanism for pre-treatment hyperthyroidismassociated neutropenia has not been completely elucidated, but Kyritsi et al (25) found that out of 218 adult patients who presented to a hematology clinic with neutropenia, 43.6\% had thyroid disease (including Graves' disease, Hashimoto's thyroiditis, patients who had undergone total thyroidectomy, nontoxic multinodular goiter, and antibodynegative subclinical hypothyroidism). Although patients who were undergoing treatment with ATDs were not excluded from the study, the authors did find that there was an inverse correlation between free T3 and the ANC $\left(r^{2}=\right.$ $0.274, p=0.007$ ), suggesting a direct toxic effect of excess thyroid hormone to granulopoiesis. This is further supported by the fact that the subgroup of patients $(n=6)$ who had total thyroidectomy and subsequent iatrogenic medicationrelated hyperthyroidism had the lowest ANC, whereas those with non-toxic multinodular goiter $(n=18)$, who were euthyroid with no detectable antithyroid antibodies, had the highest ANC. In the same study, it was also found that CD4 + lymphocytes positively correlated with TSH levels $\left(r^{2}=0.16\right.$, $p=0.045)$, but negatively with $\mathrm{T} 4$ levels $\left(r^{2}=-0.274\right.$, $p=0.024)$. The possible involvement of autoimmune antineutrophil antibodies causing hyperthyroidism-associated neutropenia has also been postulated $(4,8)$. In our study, 3/5 patients who had pre-treatment neutropenia had ANCA checked and all three were negative.

ANCA has been associated with autoimmune neutropenia, albeit a direct causal relationship has not been established. ANCA has typically been associated with vasculitides, but neutrophil destruction by antineutrophil membrane antibodies may expose neutrophil proteinase 3 and neutrophil myeloperoxidase antigens to the circulation, thereby promoting ANCA formation. It has been suggested that a positive ANCA should prompt one to think of underlying toxin exposure or other autoimmune diseases (26). MMI-associated agranulocytosis is considered a form of transient acquired neutropenia (TAN) defined as neutropenia lasting $<3$ months. The differential diagnoses for TAN include infection (especially viral infections), autoimmune neutropenia and drug-induced neutropenia (mainly anticonvulsants, sulfonamides, penicillins, antipsychotics and ATDs). Recombinant granulocyte colony stimulating factor is typically only used in these cases if the neutropenia is profound and associated with severe infection (11).
Thyrotoxicosis results in an increased response to catecholamines, particularly beta-adrenergic signaling, causing signs and symptoms such as palpitations, hypertension, and weight loss. The effects of thyroid hormone on alpha-adrenergic signaling is less clear (27). Increased beta-adrenergic activity as a result of thyrotoxicosis is less likely to be the cause of neutropenia since studies have shown that the effect of increased betaadrenergic activity on bone marrow is actually to increase neutrophil production (28).

\section{Study Limitations}

Our study is limited by its retrospective nature, small sample size, and short duration of follow-up. Larger longitudinal studies would be of benefit to elucidate if and how the thyrotoxic state or autoimmune factors correlate with ANC in pediatric patients.

\section{Conclusion}

Around $16 \%$ of pediatric and adolescent patients with $\mathrm{AIH}$ may have pre-treatment neutropenia, but in the cohort described this resolved in the short term and did not worsen with thionamides. We suggest that MMI may be used with caution in these patients with close monitoring of blood counts.

\section{Ethics}

Ethics Committee Approval: The study were approved by the New York University Faculty of Medicine's Institutional Review Board as Exempt Category 4 (study \# i19-00627).

Informed Consent: Retrospective study.

Peer-review: Externally and internally peer-reviewed.

\section{Authorship Contributions}

Concept - Design- Data Collection or Processing - Analysis or Interpretation - Literature Search - Writing: All authors.

Financial Disclosure: The authors declared that this study received no financial support.

\section{References}

1. Ross DS, Burch HB, Cooper DS, Greenlee MC, Laurberg P, Maia AL, Rivkees SA, Samuels M, Sosa JA, Stan MN, Walter MA. 2016 American Thyroid Association Guidelines for Diagnosis and Management of Hyperthyroidism and Other Causes of Thyrotoxicosis. Thyroid 2016;26:1343-1421.

2. Nakamura H, Miyauchi A, Miyawaki N, Imagawa J. Analysis of 754 cases of antithyroid drug-induced agranulocytosis over 30 years in Japan. J Clin Endocrinol Metab 2013;98:4776-4783.

3. Garla VV, Abdul Salim S, Yanes-Cardozo LL. Pancytopenia: a rare complication of Graves' disease. BMJ Case Rep. 2018 Mar 9;2018:bcr2017223887. 
4. Garcia J, França Ld, Ellinger V, Wolff M. Marrow hypoplasia: a rare complication of untreated Grave's disease. Arq Bras Endocrinol Metabol 2014;58:953-957.

5. Behera KK, Agrawal K, Adhya AK. Graves' disease with pancytopenia and hepatic dysfunction: a rare case presentation. Indian J Nucl Med 2019;34:38-41

6. Aggarwal N, Tee SA, Saqib W, Fretwell T, Summerfield GP, Razvi S. Treatment of hyperthyroidism with antithyroid drugs corrects mild neutropenia in Graves' disease. Clin Endocrinol (Oxf) 2016;85:949. 995.

7. Baagar KA, Siddique MA, Arroub SA, Ebrahim AH, Jayyousi AA. Atypical Complications of Graves' Disease: A Case Report and Literature Review. Case Rep Endocrinol 2017;2017:6087135. Epub 2017 Feb 28.

8. Pincet L, Gorostidi F. Graves Disease Causing Pancytopenia: Case Report and Literature Review. Clin Med Insights Case Rep 2018;11:1179547618781090

9. Tokushima Y, Sakanishi Y, Nagae K, Tokushima M, Tago M, Tomonaga M, Yoshioka T, Hyakutake M, Sugioka T, Yamashita S. Thyroid storm complicated by bicytopenia and disseminated intravascular coagulation. Am J Case Rep 2014;15:312-316.

10. Soeki T, Tamura Y, Kondo N, Shinohara H, Tanaka H, Bando K, Fukuda N. A case of thyrotoxicosis with pancytopenia. Endocr J 2001;48:385389 .

11. Walkovich K, Boxer LA. How to approach neutropenia in childhood Pediatr Rev 2013;34:173-184.

12. Eakin DL, Peake RL, Weiss GB. Effect of therapy on the neutropenia of hyperthyroidism. South Med J 1983;76:335-337, 340.

13. Gangadharan A, Hanumanthaiah H, Ng S. The use of iodine as first line therapy in graves' disease complicated with neutropenia at first presentation in a paediatric patient. J Adv Med Med Res 2013;3:324 328.

14. Rivkees SA, Stephenson K, Dinauer C. Adverse events associated with methimazole therapy of graves' disease in children. Int J Pediatr Endocrinol 2010;2010:176970. Epub 2010 Mar 7

15. Rabon S, Burton AM, White PC. Graves' disease in children: long-term outcomes of medical therapy. Clin Endocrinol (Oxf) 2016;85:632-635. Epub 2016 Jun 14

16. Vicente N, Cardoso L, Barros L, Carrilho F. Antithyroid Drug-Induced Agranulocytosis: State of the Art on Diagnosis and Management. Drugs R D 2017;17:91-96.

17. Federici L, Weitten T, Alt M, Blaison G, Zamfir A, Audhuy B, Maloisel F, Andrès E. Agranulocytoses médicamenteuses idiosyncrasiques
[Idiosyncratic drug-induced agranulocytosis]. Presse Med 2008;37:1327-1333. (French) Epub 2008 Jul 17

18. Andrès E, Mourot-Cottet R, Maloisel F, Séverac F, Keller O, Vogel T, Tebacher M, Weber JC, Kaltenbach G, Gottenberg JE, Goichot B, Sibilia J, Korganow AS, Herbrecht R. Idiosyncratic drug-induced neutropenia \& agranulocytosis. QJM 2017;110:299-305. Epub 2017 Jan 9

19. Takata K, Kubota S, Fukata S, Kudo T, Nishihara E, Ito M, Amino N, Miyauchi A. Methimazole-induced agranulocytosis in patients with Graves' disease is more frequent with an initial dose of $30 \mathrm{mg}$ daily than with 15 mg daily. Thyroid 2009;19:559-563.

20. Akoum R, Michel S, Wafic T, Emile B, Marwan M, Khaled H, Gerard A Myelodysplastic syndrome and pancytopenia responding to treatment of hyperthyroidism: peripheral blood and bone marrow analysis before and after antihormonal treatment. J Cancer Res Ther 2007;3:43-46.

21. Jha P, Singh YP, Ghimire B, Jha BK. Pancytopenia in a surgical patient, a rare presentation of hyperthyroidism. BMC Surg 2014;14:108.

22. Naji P, Kumar G, Dewani S, Diedrich WA, Gupta A. Graves' disease causing pancytopenia and autoimmune hemolytic anemia at different time intervals: a case report and a review of the literature. Case Rep Med 2013;2013:194542. Epub 2013 Nov 11

23. Shaw B, Mehta AB. Pancytopenia responding to treatment of hyperthyroidism: a clinical case and review of the literature. Clin Lab Haematol 2002;24:385-387.

24. Mukasa K, Ito K, Ito K. Antithyroid drug-induced hematopoietic damage: a retrospective cohort study of agranulocytosis and pancytopenia involving 50,385 patients with Graves' disease. J Clin Endocrinol Metab 2012;97:E49-E53. Epub 2011 Nov 2

25. Kyritsi EMA, Yiakoumis X, Pangalis GA, Pontikoglou C, Pyrovolaki K, Kalpadakis C, Mavroudi I, Koutala H, Mastrodemou S, Vassilakopoulos TP, Vaiopoulos G, Diamanti-Kandarakis E, Papadaki HA, Angelopoulou MK. High frequency of thyroid disorders in patients presenting with neutropenia to an outpatient hematology clinic STROBE-compliant article. Medicine (Baltimore) 2015;94:e886

26. Grayson PC, Sloan JM, Niles JL, Monach PA, Merkel PA. Antineutrophil cytoplasmic antibodies, autoimmune neutropenia, and vasculitis. Semin Arthritis Rheum 2011;41:424-433. Epub 2011 Apr 19

27. Silva JE, Bianco SD. Thyroid-adrenergic interactions: physiological and clinical implications. Thyroid 2008;18:157-165.

28. Maestroni GJM. Adrenergic Modulation of Hematopoiesis. J Neuroimmune Pharmacol 2020;15:82-92. Epub 2019 Feb 14 